\title{
Capability and Clinical Success
}

Robert L. Ferrer, MD, MPH

Alejandra Varela Carrasco, MD

'Department of Family and Community Medicine, University of Texas Health Science Center at San Antonio, San Antonio, Texas

${ }^{2}$ Austin Family Medicine Residency Program, Austin, Texas
AC Annals Journal Club selection; see inside back cover or http://www. annfammed.org/AJC/.

Conflicts of interest: none reported

\section{CORRESPONDING AUTHOR}

Robert Ferrer, MD, MPH

Department of Family and Community

Medicine

University of Texas Health Science Center

at San Antonio

7703 Floyd Curl Dr

San Antonio, TX 78229-3900

FerrerR@uthscsa.edu

\begin{abstract}
Better outcomes for chronic diseases remain elusive because success depends on events outside the control of the health care system: patients' ability to mange their health behaviors and chronic diseases. Among the most powerful influences on self-management are the social and environmental constraints on healthy living, yet the clinical response to these environmental determinants is poorly developed. A potential approach for addressing social determinants in practice, as well as planning and evaluating community responses, is the capability framework. Defined as the real opportunity to achieve a desired lifestyle, capability focuses attention on the material conditions that constrain real opportunity and how opportunity emerges from the interaction between personal resources and the social environment. Using examples relevant to chronic disease and behavior change, we discuss the clinical application of the capability framework.
\end{abstract}

Ann Fam Med 2010;8:454-460. doi:10.1370/afm.1163.

\section{CASE HISTORY}

M rs $R$. is a 48-year-old Latina who suffers from type 2 diabetes mellitus, hypertension, dyslipidemia, and obesity. She has been regularly attending appointments at the practice for 3 years. Despite ongoing adjustment of her medications, her glycosylated hemoglobin level has never been less than $8.5 \%$. Her history and refill intervals suggest that she takes her medications regularly. She has attended nutrition and diabetes education programs. Her physician, Dr M., initially believed that she was motivated to manage her illnesses but is growing increasingly frustrated by the lack of clinical progress.

\section{THE EPIDEMIOLOGICAL CONTEXT}

Unhealthy behaviors and the chronic diseases associated with them account for much of the morbidity and mortality in modern societies. Developing effective solutions is complicated by the burden of morbidity falling most heavily on those with the fewest resources. ${ }^{1-3}$ Reducing these health disparities has proved especially difficult, with little progress during the past 20 years. ${ }^{4,5}$

\section{DISCONNECT BETWEEN PROCESS AND OUTCOME IMPROVEMENTS}

In the struggle to manage chronic diseases, a growing number of clinical studies point to a disconnect between process-of-care improvements and clinical outcomes. ${ }^{6-9}$ One reason for this disconnect is that success depends on events outside the control of the health care system: patients' ability to alter unhealthy behaviors and manage their diseases. ${ }^{6}$ The chronic care model therefore emphasizes the importance of patients as active partners. To promote patient participation, clinical strategies have broadened to include more holistic concerns, such as health literacy, ${ }^{10-13}$ self-efficacy, ${ }_{1}^{14}$ and the interventions deriving from them, including patient empowerment, ${ }^{15}$ patient self-management, ${ }^{12}$ and motivational interview- 
ing. ${ }^{16}$ These approaches represent important advances, and they have improved outcomes. ${ }^{12,17}$ Yet they are themselves limited in scope. They aim to enhance patients' confidence, motivation, and problem-solving skills, but place less emphasis on evaluating whether the external environment offers real opportunities for change.$^{18}$ For example a review of the current national standards for diabetes self-management education ${ }^{19}$ shows limited guidance beyond a general recommendation for "developing personal strategies to promote health and behavior change." This failure to sufficiently account for social determinants of health may be one reason that the interventions remain only modestly effective. ${ }^{20-26}$ In communities with few resources to support healthy behaviors, even knowledgeable and motivated patients can be defeated. ${ }^{27,28}$

\section{A CONSTRAINT: ENVIRONMENTAL BARRIERS TO HEALTHY BEHAVIORS}

The social and physical environment is a key determinant of health behaviors. Population-level studies find significant variation in local opportunities and supports for health behavior change. ${ }^{18,29-37}$ For example, the retail landscape of low-income neighborhoods is likely to include few large supermarkets but many liquor stores, fast-food outlets, and convenience stores. ${ }^{38-40}$ Where supermarkets are scarce, healthy food is less available and more expensive. ${ }^{41}$ Even when present, supermarkets in low-income neighborhoods stock fewer healthy alternatives and lower-quality produce. And restaurants in low-income areas tend to offer fewer healthy options and more heavily promote their unhealthy menu items. ${ }^{42-45}$

Residents of less-affluent neighborhoods also face obstacles to physical activity. Unsafe neighborhoods limit options for outdoor activity, and there may be few affordable options for joining fitness or recreation centers. The time necessary to participate in physical activity is another barrier. ${ }^{46-49}$

The net effect of these environmental barriers is that residents of disadvantaged neighborhoods eat lesshealthy diets, engage in less physical activity, and have a higher prevalence of obesity. ${ }^{44,48,50-52}$ Although these associations may be partially due to selection effects from people who value healthier behaviors choosing to live in more enabling neighborhoods, ${ }^{47}$ the realities of economic segregation mean that disadvantaged populations are often concentrated in neighborhoods with fewer resources for healthy living. ${ }^{53-55}$

In summary, one of the limitations of current approaches for promoting self-management is that they often fail to account for common situational and environmental barriers that are among the structural causes of health disparities. Although public health interventions ${ }^{56-60}$ to address these barriers will continue to be necessary to prevent avoidable morbidity, developing effective clinic-based methods is also important, given that primary care maintains a high population contact rate. ${ }^{61}$

\section{PATIENT CAPABILITY AS A DETERMINANT OF CLINICAL SUCCESS}

The capability framework was created to evaluate individual well-being and its social context. ${ }^{62}$ In this framework, capability is defined as the extent to which people have the opportunity to live the kind of life they value. ${ }^{63}$ Value can derive from activities, such as eating well, or achievements, such as being well-nourished, and it also encompasses higher-level goals, such as being independent enough to make one's own decisions. What distinguishes the capability framework from other approaches to evaluation is its emphasis on opportunity as well as achievement. Turning raw capacity (eg, the ability to walk) into action (walking for 60 minutes a day) to achieve a goal (being physically fit) requires that there be real opportunities to do so. ${ }^{63,64}$ Examining the set of potential opportunities that are viable for a given person (a capability set) helps to define what goals are attainable. ${ }^{65}$ For instance, a capability set for physical activity would encompass the various modes and durations of physical activity that are realistically achievable given a person's constraints of time, money, support from others, physical abilities, and what is locally available.

Including opportunity as a measure of well-being helps avoid problems that arise when achievements are the sole yardstick. ${ }^{66}$ A difficulty with measuring individual well-being by achievements is that not everyone values the same achievements. Instead, the capability approach presupposes that what all people do value is the opportunity to pursue the goals that are important to them. This expanded focus recognizes the importance of individual agency. ${ }^{67}$ It is also sensitive to how agency can be diminished by entrenched deprivations, as people with few opportunities adjust their expectations downward ${ }^{68,69}$ In those situations, taking low expectations at face value may help perpetuate standing inequalities. ${ }^{70}$

At the community level, the capability approach seeks to shift the view on behavior change away from framing in terms of noninterference-" no one is stopping you from eating healthy food" — and toward considering positive such supports as the availability of fruit and vegetables in neighborhood markets. ${ }^{63}$ From this perspective, without support for healthy lifestyles, the freedom to pursue health is illusory for those with the will but not the means to do so. 
As we consider various kinds of community support, the capability approach reminds us that providing resources is not enough without also considering how they will serve people with an array of nuanced needs. Does the list of community resources meet the needs of working families? Is the new park accessible to those without cars? Recognizing that people differ in their ability to turn primary resources into desired outcomes discourages formulaic solutions; the key question is not whether the community offers everyone the same resources but whether it offers everyone the conditions to thrive. ${ }^{64}$

A capability perspective implies that poverty should not be defined primarily by income but by scarce opportunity to pursue valued activities and goals. Strong external supports create opportunities that enable people with limited income to pursue their goals for healthy living. ${ }^{71}$ Capability is thus a key mediator of the relationship between socioeconomic position and outcomes.

As the preceding discussion indicates, capability cannot be understood as a disconnected individual attribute. Instead, capability emerges from the interaction of person and environment. A neighborhood without grocery stores is an inconvenience for someone who owns a car but a major obstacle for someone who does not-unless there is good public transportation. So it would make no sense, for example, to consider what a disabled person might realistically achieve without also exploring what resources are available in the community.

Thinking systematically about capability calls for attention to 3 sets of factors (Table 1). Considering them together will help illuminate the interdependence of choices, resources, and contexts. First, what are the patient's choices—values and goals-for this health issue? The capability framework recognizes that individual choice and motivation are important determinants of behavior-in the absence of motivation, opportunity is irrelevant. Yet the observation that people will nar-

\section{Table 1. Evaluating Real Opportunities and Potential Interventions}

\begin{tabular}{ll}
\hline Assessment & 1. What are person's values and goals with respect \\
to this health issue? & 2. What resources are locally available? Is there \\
opportunity to access them? How convenient are \\
they? What is the price? \\
3. What personal, family, or community factors \\
help or hinder using those resources? \\
Intervention What is the functional goal? Is there an opportu- \\
nity to achieve the function in another way? \\
2. What personal, family, or community assets can \\
be leveraged to increase opportunity? \\
3. Can the social context be addressed through \\
community action or advocacy?
\end{tabular}

row their aspirations in impoverished environments calls for careful exploration without being paternalistic. If new opportunities could be identified, would the person value the goals differently? Second, what material resources does the person have available? The answer will help define the boundaries of what is achievable. Considerations include the goods and services locally available at a given cost and whether the person has adequate financial resources to access them. Third, what is the person's ability to turn those resources into real opportunities? A wide range of factors influences the ability to exploit available resources. Among these factors are literacy, physical or mental disability, social and cultural norms, discrimination, and status within the home, workplace, and society. For example, within a single household, be it affluent or poor, there may be crucial differences in the real opportunities for healthy behaviors because of power imbalances in gender roles. ${ }^{72}$ Other nonmaterial factors that would be important to assess include decision-making strategies, interpersonal skills, social networks, and group memberships, such as churches or community organizations. ${ }^{67}$

\section{CLINICAL APPLICATION}

The capability framework is in its early stages of development for health and health care applications. ${ }^{67,73,74}$ The intent here is to discuss its potential use in the clinical and community contexts of primary care and to provoke further discussion, development, and evaluation.

Perhaps most importantly, capability can be used as an organizing framework for addressing lifestyle change and chronic disease self-management. In this role, it has several benefits. Understanding the interaction among environment, opportunity, and choice assembles a fuller context for understanding patients' progress in lifestyle change. ${ }^{18}$ The questions in Table 2 illustrate areas of inquiry when assessing capability for changes in diet or physical activity. Identifying patients with few real opportunities for change may prevent the delay inherent in repeated cycles of advice followed by failure and frustration. ${ }^{31,75}$ Instead, energy can be redirected to problem solving. Conversely, recognizing and building on existing assets can help reduce resignation and dependence. ${ }^{76}$ Communities often include people who thrive despite adverse environments. Their wisdom and strategies for leveraging local resources can sometimes be turned into larger programs. ${ }^{77}$

When capability is limited, two interventions may be appropriate. If community resources to enhance opportunity are available, the next step is to connect patients with resources that support healthy behaviors. ${ }^{78}$ Preliminary evidence suggests that practices with strategies in place to identify patients with low physical activity 


\begin{tabular}{l} 
Table 2. Assessing Patients' Capability in Diet and \\
Physical Activity \\
\hline How easy is it to get to a grocery store for food shopping? \\
Are fresh fruits and vegetables for sale where you usually shop for food? \\
Can you afford to buy fresh fruits and vegetables? \\
Is there a place where you can grow food in your yard or your neighborhood? \\
Do you have time to fix your own meals? \\
Do you have family who can help you fix meals? \\
At home, are you free to eat the foods that doctors or dietitians have said \\
you should eat? \\
Do you have the chance to be physically active? \\
It is convenient for you to be physically active several days a week? \\
Is being physically active a daily part of your job? \\
Do you have time each day to be physically active? \\
Do you have convenient places to be physically active outside [indoors]? \\
Do you have safe places to be physically active outside [indoors]? \\
Can you afford to join a health or fitness club where you can exercise? \\
Do other people help free your time to be physically active? \\
Does your spouse/partner make it easier for you to be physically active? \\
Are there people to help watch your kids while you exercise? \\
Do you have other duties [such as caring for a parent] that make it hard to be \\
physically active?
\end{tabular}

To be successful, community resources must be available, accessible, affordable, and effective. ${ }^{81}$ Several types of community connections can increase patients' opportunities for successful change, including community health workers, partnerships with local public health authorities, and collaboration with community groups. One model is for community health workers to assist patients with instrumental or relationship support, such as providing companionship for walks, motivational messages, or mobilizing the assistance of family. ${ }^{88-91}$ Arrangements where community health workers are closely integrated with the practice allow for continuous cycles of assistance, feedback, and tracking progress with the clinical team. ${ }^{92}$ By bridging the perspectives and worldviews of practice and community, community health workers may also help clinical teams better understand the local barriers to healthy living. ${ }^{93}$ Beyond aiding individual patients, community health workers often enhance capability through local activism to promote healthier physical and and link them with practice or community resources for change are more likely to achieve high rates of physical activity. ${ }^{79}$ Most practices' current capacity to make these connections is limited and will need development, ${ }^{80}$ but experience with bridging practice and community resources is growing, providing useful guidance. ${ }^{81}$ To cope with the varied needs presented by patients with different levels of affluence, literacy, and mobility, as well as varying cultural backgrounds, it is helpful to be able to offer a menu of different community resources. Because the type of community resources available will vary, clinicians and practice staff need to be knowledgeable about what is available locally. Creating a local referral guide for clinicians' use can help. Flocke and others $^{82,83}$ have created a useful method to assemble a guide, but a more promising emerging model is a local connector available to help patients select the appropriate resource for their situation. The connector function has been carried out by trained staff, such as medical assistants ${ }_{,}^{84}$ or community liaisons shared across practices, ${ }^{85}$ or by Web portals, ${ }^{86}$ all of which have been shown to increase connections with community referrals. A potential advantage of the connector model is that the connector can help manage the referral after the initial contact, checking patients' progress, providing reminders, or even delivering more sophisticated behavioral change counseling. ${ }^{85}$ North Carolina's recent experience has shown the feasibility and effectiveness of a collaborative arrangement in which practices share community resources that enable patients to better manage their chronic diseases. ${ }^{87}$ retail environments. ${ }^{18,94}$ Evidence that these community health worker interventions improve outcomes is now available from a number of studies. ${ }^{89,92,95,96}$

Partnerships with local public health agencies remain an underused opportunity. Primary care practices and local health departments embrace many of the same prevention goals and provide overlapping care for disadvantaged populations, but they often poorly coordinate their services. Front-line clinicians are in an excellent position to provide community intelligence on needed resources, whereas health departments' outreach and education programs can directly enhance patients' capability in disease prevention and health promotion. ${ }^{97}$

Grassroots community groups can be helpful partlizing the community to create new opportunities for healthy living. ${ }^{98}$ An example of the latter is the creation of minimarkets to sell produce in communities that lack traditional grocery stores. ${ }^{99}$ Practitioners seeking to forge linkages with community groups will find guidance in the principles of community-oriented primary care. ${ }^{100,101}$

When communities lack the resources necessary to support capability, practices should advocate for what is needed. ${ }^{102}$ The capability framework can be used to help guide the development of solutions, keeping the focus on expanding opportunities for people across the spectrum of assets and needs. Practices can choose their level of involvement, but it helps to remain sufficiently engaged to shape a result that is well-integrated with the practice. ${ }^{103}$ ners as well, providing direct aid for patients and mobi- 


\section{CASE OUTCOME}

With a short series of capability questions to Mrs R. about her situation, Dr M. learned the following facts: Mrs R.'s neighborhood lacks a full-service grocery store. She does not own a car and depends on her adult son to drive her to a distant grocery to buy her food. His availability does not always coincide with her needs, so she must do quite a bit of fill-in shopping at local convenience stores that do not stock fresh produce or other healthy alternatives. Although she tries to plan her shopping around the menus her nutritionist provided, her husband, who is also a diabetic, dislikes the recommended meals and refuses to eat them more than once or twice a week. Also, she sometimes struggles to find the time to prepare meals at home because she cares for 2 young grandchildren at her daughter's residence. On the evenings when her daughter returns home late, she and her husband eat at one of the nearby fast-food outlets.

Dr M. connected Mrs R. with a community-based group that trains promotores to assist patients with managing their diabetes. Mrs R. attended several culturally relevant cooking classes at the group's center, learning how to make meals that would be more palatable to her husband while still meeting their dietary needs. The instructor recommended preparing meals in larger quantities once or twice a week so the extra portions could be stored and quickly reheated on the nights when time is short. A promotora was also able to introduce Mrs R. to a nearby neighbor for shared shopping trips.

\section{FRAMEWORK FOR SUCCESS}

Patients with good health literacy and self-management skills can nonetheless be defeated when they lack the resources to put those skills into action. Although policy approaches are ultimately necessary to address the underlying social determinants of health, the failure to develop a systematic clinical response to the pervasive environmental barriers to healthy living continues to slow progress in managing chronic disease.

The significance of the capability approach is that it expands the informational basis for making clinical assessments, illuminating areas where patients' knowledge and motivation may be hobbled by difficult circumstances. By focusing on external as well as internal supports, the capability framework can potentially augment the effectiveness of self-management and empowerment strategies. It may also help to more efficiently manage health behaviors and chronic diseases by prospectively identifying patients who are at high risk of failing to change key behaviors. Attention and additional resources can then be focused on this at-risk patient subset without having to rely on broad indicators, such as race or educational level, that risk misclassifying patients with adequate capability to achieve change.

To read or post commentaries in response to this article, see it online at http://www.annfammed.org/cgi/content/full/8/5/454.

Key words: Health care disparities; delivery of health care/organization $\varepsilon$ administration; social environment; models, theoretical; health behaviors

Submitted June 6, 2009; submitted, revised March 2, 2010; accepted March 15, 2010.

\section{References}

1. Wong MD, Shapiro MF, Boscardin WJ, Ettner SL. Contribution of major diseases to disparities in mortality. N Engl J Med. 2002;347 (20):1585-1592.

2. Mokdad AH, Marks JS, Stroup DF, Gerberding JL. Actual causes of death in the United States, 2000. JAMA. 2004;291(10):1238-1245.

3. Adler NE, Rehkopf DH. U.S. disparities in health: descriptions, causes, and mechanisms. Annu Rev Public Health. 2008;29:235-252.

4. Krieger N, Rehkopf DH, Chen JT, Waterman PD, Marcelli E, Kennedy $M$. The fall and rise of US inequities in premature mortality: 1960-2002. PLoS Med. 2008;5(2):e46.

5. Ezzati M, Friedman AB, Kulkarni SC, Murray CJL. The reversal of fortunes: trends in county mortality and cross-county mortality disparities in the United States. PLoS Med. 2008;5(4):e66.

6. Landon BE, Hicks LS, O'Malley AJ, et al. Improving the management of chronic disease at community health centers. $N$ Engl J Med. 2007;356(9):921-934.

7. Saaddine JB, Cadwell B, Gregg EW, et al. Improvements in diabetes processes of care and intermediate outcomes: United States, 19882002. Ann Intern Med. 2006;144(7):465-474.

8. Kuo S, Fleming BB, Gittings NS, et al. Trends in care practices and outcomes among Medicare beneficiaries with diabetes. Am J Prev Med. 2005;29(5):396-403.

9. Trivedi AN, Zaslavsky AM, Schneider EC, Ayanian JZ. Trends in the quality of care and racial disparities in Medicare managed care. N Engl J Med. 2005;353(7):692-700.

10. Wagner EH, Austin BT, Von Korff M. Organizing care for patients with chronic illness. Milbank Q. 1996;74(4):511-544.

11. Wagner EH, Austin BT, Von Korff M. Improving outcomes in chronic illness. Manag Care Q. 1996;4(2):12-25.

12. Lorig KR, Holman HR. Self-management education: history, definition, outcomes, and mechanisms. Ann Behav Med. 2003;26(1):1-7.

13. Institute of Medicine. Health Literacy: A Prescription to End Confusion. Nielsen-Bohlman L, Panzer AM, Kindig DA eds. Washington, DC: National Academies Press; 2004.

14. Bandura A. Human agency in social cognitive theory. Am Psychol. 1989;44(9):1175-1184.

15. Funnell MM, Anderson RM, Arnold MS, et al. Empowerment: an idea whose time has come in diabetes education. Diabetes Educ. 1991;17(1):37-41.

16. Miller WR. Motivational interviewing with problem drinkers. Behav Cogn Psychother. 2009;11:147-172.

17. Burke BL, Arkowitz H, Menchola M. The efficacy of motivational interviewing: a meta-analysis of controlled clinical trials. J Consult Clin Psychol. 2003;71(5):843-861.

18. Fisher EB, Brownson CA, O'Toole ML, Shetty G, Anwuri VV, Glasgow RE. Ecological approaches to self-management: the case of diabetes. Am J Public Health. 2005;95(9):1523-1535.

19. Funnell MM, Brown TL, Childs BP, et al. National standards for diabetes self-management education. Diabetes Care. 2008;31(Suppl 1): s97-S104. 
20. Rothman RL, DeWalt DA, Malone $\mathrm{R}$, et al. Influence of patient literacy on the effectiveness of a primary care-based diabetes disease management program. JAMA. 2004;292(14):1711-1716.

21. Morris NS, MacLean CD, Littenberg B. Literacy and health outcomes: a cross-sectional study in 1002 adults with diabetes. BMC Fam Pract. 2006;7:49.

22. Wolf MS, Gazmararian JA, Baker DW. Health literacy and health risk behaviors among older adults. Am J Prev Med. 2007;32(1):19-24.

23. Anderson RM, Funnell MM, Nwankwo R, Gillard ML, Oh M, Fitzgerald JT. Evaluating a problem-based empowerment program for African Americans with diabetes: results of a randomized controlled trial. Ethn Dis. 2005;15(4):671-678.

24. VanWormer JJ, Boucher JL. Motivational interviewing and diet modification: a review of the evidence. Diabetes Educ. 2004;30(3): 404-406, 408-410, 414-416 passim.

25. Resnicow K, Jackson A, Wang T, et al. A motivational interviewing intervention to increase fruit and vegetable intake through Black churches: results of the Eat for Life trial. Am J Public Health. 2001; 91(10):1686-1693.

26. Pignone M, DeWalt DA, Sheridan S, Berkman N, Lohr KN. Interventions to improve health outcomes for patients with low literacy. A systematic review. J Gen Intern Med. 2005;20(2):185-192.

27. Link BG, Phelan JC. Understanding sociodemographic differences in health-the role of fundamental social causes. Am J Public Health. 1996;86(4):471-473.

28. Karter AJ, Stevens MR, Herman WH, et al.; Translating Research Into Action for Diabetes Study Group. Out-of-pocket costs and diabetes preventive services: the Translating Research Into Action for Diabetes (TRIAD) study. Diabetes Care. 2003;26(8):2294-2299.

29. Finkelstein EA, Ruhm CJ, Kosa KM. Economic causes and consequences of obesity. Annu Rev Public Health. 2005;26:239-257.

30. Hill JO, Peters JC. Environmental contributions to the obesity epidemic. Science. 1998;280(5368):1371-1374.

31. Glasgow RE, Toobert DJ. Social environment and regimen adherence among type II diabetic patients. Diabetes Care. 1988;11(5):377-386.

32. Dagogo-Jack S, Funnell MM, Davidson J. Barriers to achieving optimal glycemic control in a multi-ethnic society: a US focus. Curr Diabetes Rev. 2006;2(3):285-293.

33. Ebbeling CB, Pawlak DB, Ludwig DS. Childhood obesity: publichealth crisis, common sense cure. Lancet. 2002;360(9331):473-482.

34. Morland K, Wing S, Diez Roux A, Poole C. Neighborhood characteristics associated with location of food stores and food service places. Am J Prev Med. 2001;22(1):23-29.

35. Joshu CE, Boehmer TK, Brownson RC, Ewing R. Personal, neighbourhood and urban factors associated with obesity in the United States. J Epidemiol Community Health. 2008;62(3):202-208.

36. Anderson LM, Scrimshaw SC, Fullilove MT, Fielding JE; Task Force on Community Preventive Services. The Community Guide's model for linking the social environment to health. Am J Prev Med. 2003; 24(3)(Suppl):12-20.

37. Betancourt JR, Quinlan J. Personal responsibility versus responsible options: health care, community health promotion, and the battle against chronic disease. Prev Chronic Dis. 2007;4(3):1-3.

38. LaVeist TA, Wallace JM Jr. Health risk and inequitable distribution of liquor stores in African American neighborhood. Soc Sci Med. 2000;51(4):613-617.

39. Powell LM, Slater S, Mirtcheva D, Bao Y, Chaloupka FJ. Food store availability and neighborhood characteristics in the United States. Prev Med. 2007;44(3):189-195.

40. Ford PB, Dzewaltowski DA. Disparities in obesity prevalence due to variation in the retail food environment: three testable hypotheses. Nutr Rev. 2008;66(4):216-228.
41. Chung C, Myers SL. Do the poor pay more for food? An analysis of grocery store availability and food price disparities. J Consum Aff. 1999;33(2):276-296.

42. Andreyeva T, Blumenthal DM, Schwartz MB, Long MW, Brownell KD. Availability and prices of foods across stores and neighborhoods: the case of New Haven, Connecticut. Health Aff (Millwood). 2008;27(5):1381-1388.

43. Horowitz CR, Colson KA, Hebert PL, Lancaster K. Barriers to buying healthy foods for people with diabetes: evidence of environmental disparities. Am J Public Health. 2004;94(9):1549-1554

44. Morland K, Wing S, Diez Roux A. The contextual effect of the local food environment on residents' diets: the atherosclerosis risk in communities study. Am J Public Health. 2002;92(11):1761-1767.

45. Lewis LB, Sloane DC, Nascimento LM, et al.; REACH Coalition of the African Americans Building a Legacy of Health Project. African Americans' access to healthy food options in South Los Angeles restaurants. Am J Public Health. 2005;95(4):668-673.

46. Humpel N, Owen N, Leslie E. Environmental factors associated with adults' participation in physical activity: a review. Am J Prev Med. 2002;22(3):188-199.

47. Williams C. The Built Environment and Physical Activity: What is the Relationship? Princeton, NJ: Robert Wood Johnson Foundation; 2007.

48. Gordon-Larsen P, Nelson MC, Page P, Popkin BM. Inequality in the built environment underlies key health disparities in physical activity and obesity. Pediatrics. 2006;117(2):417-424.

49. Albanes D, Conway JM, Taylor PR, Moe PW, Judd J. Validation and comparison of eight physical activity questionnaires. Epidemiology. 1990;1(1):65-71.

50. Moore LV, Diez Roux AV, Nettleton JA, Jacobs DR Jr. Associations of the local food environment with diet quality-a comparison of assessments based on surveys and geographic information systems: the multi-ethnic study of atherosclerosis. Am J Epidemiol. 2008;167(8):917-924.

51. Nelson MC, Gordon-Larsen P, North KE, Adair LS. Body mass index gain, fast food, and physical activity: effects of shared environments over time. Obesity (Silver Spring). 2006;14(4):701-709.

52. Papas MA, Alberg AJ, Ewing R, Helzlsouer KJ, Gary TL, Klassen AC. The built environment and obesity. Epidemiol Rev. 2007;29:129-143.

53. Waitzman NJ, Smith KR. Separate but lethal: the effects of economic segregation on mortality in metropolitan America. Milbank Q. 1998;76(3):341-73, 304

54. Massey D, Denton N. American Apartheid: Segregation and the Making of the American Underclass. Cambridge, MA: Harvard University Press; 1993.

55. Schulz AJ, Williams DR, Israel BA, Lempert LB. Racial and spatial relations as fundamental determinants of health in Detroit. Milbank Q. 2002;80(4):677-707, iv.

56. Sorensen G, Emmons K, Hunt MK, et al. Model for incorporating social context in health behavior interventions: applications for cancer prevention for working-class, multiethnic populations. Prev Med. 2003;37(3):188-197.

57. Marmot M, Wilkinson RG. Social Determinants of Health. Oxford: Oxford University Press; 2005.

58. Krieger $\mathrm{N}$. Theories for social epidemiology in the 21st century: an ecosocial perspective. Int J Epidemiol. 2001;30(4):668-677.

59. Kahn EB, Ramsey LT, Brownson RC, et al. The effectiveness of interventions to increase physical activity. A systematic review. Am J Prev Med. 2002;22(4)(Suppl):73-107.

60. Matson-Koffman DM, Brownstein JN, Neiner JA, Greaney ML. A site-specific literature review of policy and environmental interventions that promote physical activity and nutrition for cardiovascular health: what works? Am J Health Promot. 2005;19(3):167-193. 
61. Ferrer RL. Pursuing equity: contact with primary care and specialist clinicians by demographics, insurance, and health status. Ann Fam Med. 2007;5(6):492-502.

62. Sen AK. Commodities and Capabilities. Amsterdam: North-Holland; 1985.

63. Sen A. Inequality Reexamined. Oxford: Oxford University Press; 1992.

64. Robeyns I. The capability approach in practice. J Polit Philos. 2006; 14(3):351-376.

65. Sen A. Development as Freedom. New York, NY: Alfred A. Knopf; 1999.

66. Ruger JP. Ethics of the social determinants of health. Lancet. 2004; 364:1094-1097.

67. Ruger JP. Health capability: conceptualization and operationalization. Am J Public Health. 2010;100(1):41-49.

68. Gould M. Race and theory: culture, poverty, and adaptation to discrimination in Wilson and Ogbu. Sociol Theory. 1999;17(2):171-200.

69. Shin HR. A new insight into urban poverty: the culture of capability poverty amongst Korean immigrant women in Los Angeles. Urban Stud. 2008;45(4):871.

70. Coast J, Smith R, Lorgelly P. Should the capability approach be applied in health economics? Health Econ. 2008;17(6):667-670.

71. Sen A. The economics of life and death. Sci Am. 1993;268(5):40-47.

72. Agarwal B, Humphries J, Robeyns I. Sen's capability approach and gender inequality: selecting relevant capabilities. Fem Econ. 2003;9(2-3):61-92.

73. Anand P, Hunter G, Smith R. Capabilities and well-being: evidence based on the Sen-Nussbaum approach to welfare. Soc Indic Res. 2005;74:9-55.

74. Coast J, Flynn TN, Natarajan L, et al. Valuing the ICECAP capability index for older people. Soc Sci Med. 2008;67(5):874-882.

75. Akimoto M, Fukunishi I, Kanno K, et al. Psychosocial predictors of relapse among diabetes patients: a 2-year follow-up after inpatient diabetes education. Psychosomatics. 2004;45(4):343-349.

76. Friedman SR, Mateu-Gelabert $P$, Sandoval M, Hagan $H$, Des Jarlais DC. Positive deviance control-case life history: a method to develop grounded hypotheses about successful long-term avoidance of infection. BMC Public Health. 2008;8:94.

77. Marsh DR, Schroeder DG, Dearden KA, Sternin J, Sternin M. The power of positive deviance. BMJ. 2004;329(7475):1177-1179.

78. Woolf SH, Glasgow RE, Krist A, et al. Putting it together: finding success in behavior change through integration of services. Ann Fam Med. 2005;3(Suppl 2):S20-S27.

79. Balasubramanian BA, Cohen DJ, Clark EC, et al. Practice-level approaches for behavioral counseling and patient health behaviors. Am J Prev Med. 2008;35(5)(Suppl):S407-S413.

80. Meyers DS, Clancy CM. Primary care: too important to fail. Ann Intern Med. 2009;150(4):272-273.

81. Etz RS, Cohen DJ, Woolf SH, et al. Bridging primary care practices and communities to promote healthy behaviors. Am J Prev Med. 2008;35(5)(Suppl):S390-\$397.

82. O'Loughlin J, Makni H, Tremblay M, et al. Smoking cessation counseling practices of general practitioners in Montreal. Prev Med. 2001;33(6):627-638

83. Flocke SA, Gordon LE, Pomiecko GL. Evaluation of a community health promotion resource for primary care practices. Am J Prev Med. 2006;30(3):243-251.

84. Ferrer RL, Mody-Bailey P, Jaén CR, Gott S, Araujo S. A medical assistant-based program to promote healthy behaviors in primary care. Ann Fam Med. 2009;7(6):504-512.

85. Holtrop JS, Dosh SA, Torres T, Thum YM. The community health educator referral liaison (CHERL): a primary care practice role for promoting healthy behaviors. Am J Prev Med. 2008;35(5)(Suppl): S365-S372.
86. Krist $\mathrm{AH}$, Woolf SH, Frazier CO, et al. An electronic linkage system for health behavior counseling effect on delivery of the $5 A^{\prime} \mathrm{s}$. Am J Prev Med. 2008;35(5)(Suppl):S350-S358.

87. Steiner BD, Denham AC, Ashkin E, Newton WP, Wroth T, Dobson LA Jr. Community care of North Carolina: improving care through community health networks. Ann Fam Med. 2008;6(4):361-367.

88. Richert ML, Webb AJ, Morse NA, O’Toole ML, Brownson CA. Move More Diabetes: using Lay Health Educators to support physical activity in a community-based chronic disease self-management program. Diabetes Educ. 2007;33(Suppl 6):179S-184S.

89. Ingram M, Torres E, Redondo F, Bradford G, Wang C, O'Toole ML. The impact of promotoras on social support and glycemic control among members of a farmworker community on the US-Mexico border. Diabetes Educ. 2007;33(Suppl 6):172S-178S.

90. Gary TL, Batts-Turner M, Bone LR, et al. A randomized controlled trial of the effects of nurse case manager and community health worker team interventions in urban African-Americans with type 2 diabetes. Control Clin Trials. 2004;25(1):53-66

91. Davis KL, O'Toole ML, Brownson CA, Llanos P, Fisher EB. Teaching how, not what: the contributions of community health workers to diabetes self-management. Diabetes Educ. 2007;33(Suppl 6):208S-215S

92. Joshu CE, Rangel L, Garcia O, Brownson CA, O'Toole ML. Integration of a promotora-led self-management program into a system of care. Diabetes Educ. 2007;33(Suppl 6):151S-158S.

93. Witmer A, Seifer SD, Finocchio L, Leslie J, O'Neil EH. Community health workers: integral members of the health care work force. Am J Public Health. 1995;85(8 Pt 1):1055-1058.

94. Farquhar SA, Michael YL, Wiggins N. Building on leadership and social capital to create change in 2 urban communities. Am J Public Health. 2005;95(4):596-601.

95. Liebman J, Heffernan D, Sarvela P. Establishing diabetes self-management in a community health center serving low-income Latinos. Diabetes Educ. 2007;33(Suppl 6):132S-138S.

96. Fisher EB, Brownson CA, O'Toole ML, Anwuri VV, Shetty G. Perspectives on self-management from the Diabetes Initiative of the Robert Wood Johnson Foundation. Diabetes Educ. 2007;33(Suppl 6):216S-224S.

97. Horsley K, Ciske SJ. From neurons to King County neighborhoods: partnering to promote policies based on the science of early childhood development. Am J Public Health. 2005;95(4):562-567.

98. Geiger HJ. Community-oriented primary care: a path to community development. Am J Public Health. 2002;92(11):1713-1716.

99. Schulz AJ, Zenk S, Odoms-Young A, et al. Healthy eating and exercising to reduce diabetes: exploring the potential of social determinants of health frameworks within the context of community-based participatory diabetes prevention. Am J Public Health. 2005;95(4):645-651

100. Nutting PA. Community-Oriented Primary Care: From Principle to Practice. Washington, DC: US Department of Health and Human Services; 1987.

101. Mullan F, Epstein L. Community-oriented primary care: new relevance in a changing world. Am J Public Health. 2002;92(11): 1748-1755

102. Brownson CA, O'Toole ML, Shetty G, Anwuri VV, Fisher EB. Cliniccommunity partnerships: a foundation for providing community supports for diabetes care and self-management. Diabetes Spectrum 2007;20(4):209.

103. Glasgow RE, Goldstein MG, Ockene JK, Pronk NP. Translating what we have learned into practice. Principles and hypotheses for interventions addressing multiple behaviors in primary care. Am J Prev Med. 2004;27(2)(Suppl):88-101. 